\title{
Local interneurons and projection neurons in the antennal lobe from a spiking
}

\section{point of view}

\author{
Anneke Meyer, ${ }^{1,2}$ C. Giovanni Galizia, ${ }^{2}$ and Martin Paul Nawrot ${ }^{1,3}$ \\ ${ }^{1}$ Neuroinformatik/Theoretical Neuroscience, Institute of Biology, Freie Universität Berlin, Berlin, Germany; ${ }^{2}$ Department of \\ Biology, University of Konstanz, Konstanz, Germany; and ${ }^{3}$ Bernstein Center for Computational Neuroscience Berlin, \\ Berlin, Germany
}

Meyer A, Galizia CG, Nawrot MP. Local interneurons and projection neurons in the antennal lobe from a spiking point of view. J Neurophysiol 110: 2465-2474, 2013. First published September 4 2013; doi:10.1152/jn.00260.2013.-Local computation in microcircuits is an essential feature of distributed information processing in vertebrate and invertebrate brains. The insect antennal lobe represents a spatially confined local network that processes high-dimensional and redundant peripheral input to compute an efficient odor code. Social insects can rely on a particularly rich olfactory receptor repertoire, and they exhibit complex odor-guided behaviors. This corresponds with a high anatomical complexity of their antennal lobe network. In the honeybee, a large number of glomeruli that receive sensory input are interconnected by a dense network of local interneurons (LNs). Uniglomerular projection neurons (PNs) integrate sensory and recurrent local network input into an efficient spatio-temporal odor code. To investigate the specific computational roles of LNs and PNs, we measured several features of sub- and suprathreshold singlecell responses to in vivo odor stimulation. Using a semisupervised cluster analysis, we identified a combination of five characteristic features as sufficient to separate LNs and PNs from each other, independent of the applied odor-stimuli. The two clusters differed significantly in all these five features. PNs showed a higher spontaneous subthreshold activation, assumed higher peak response rates and a more regular spiking pattern. LNs reacted considerably faster to the onset of a stimulus, and their responses were more reliable across stimulus repetitions. We discuss possible mechanisms that can explain our results, and we interpret cell-type-specific characteristics with respect to their functional relevance.

honeybee; electrophysiology; cluster analysis; response latency; coefficient of variation; Fano factor; olfaction

SENSORY COMPUTATION IN THE nervous systems of both invertebrates and vertebrates is organized in local networks containing microcircuits that integrate local feed-forward and recurrent connections and constitute functional subunits of the global sensory network. Understanding the computational principles of these microcircuits is a key to a deeper understanding of sensory processing and perception (Chou et al. 2010; Shepherd 2010). As a common principle, microcircuits are built from synapses between two general types of neurons, local interneurons (LNs) and projection neurons (PNs). Neurites of LNs are spatially confined to a local brain structure, while PNs connect between brain structures. Both network connectivity and the individual morphological and physiological properties of LNs

Address for reprint requests and other correspondence: M. P. Nawrot, Königin - Luise Straße, Strasse 1-3, 14195 Berlin Dahlem, Germany (e-mail: martin.nawrot@fu-berlin.de). and PNs define the function and reflect the specific processing demands of a particular sensory system.

Primary olfactory centers, the vertebrate olfactory bulb and the analog invertebrate antennal lobe (AL), perform complex local computations (Olsen and Wilson 2008a; Sachse et al. 2006; Strowbridge 2010) that reflect the high dimensionality of the chemical olfactory space (Guerrieri et al. 2005; Haddad et al. 2008; Schmuker and Schneider 2007; Wilson and Mainen 2006) as well as the complex temporal dynamics of natural odor stimuli (Meyer and Galizia 2012; Nagel and Wilson 2011; Riffell et al. 2009; Stopfer et al. 2003). At the heart of these computations are the glomeruli, prominent examples of sensory microcircuits. In these spherical structures of high synaptic density, peripheral input from olfactory sensory neurons (OSNs) converges onto LNs and PNs. In the present study, we explore differences in in vivo response properties between LNs and PNs in the primary olfactory center of the honeybee.

In the invertebrate, structural complexity of the AL correlates with the complexity of odor-guided behavior in individual species. Anatomical complexity is particularly pronounced in social insects such as bees and ants (Galizia and Rössler 2010; Kelber et al. 2010; Martin et al. 2011; Zube and Rössler 2008). The LN network interconnects different glomeruli and thus plays an essential role in olfactory information processing (Abraham et al. 2004; Chou et al. 2010; Flanagan and Mercer 1989; Galizia and Kimmerle 2004; Kazama and Wilson 2009; Krofczik et al. 2009; Meyer and Galizia 2012; Olsen and Wilson 2008b; Sachse and Galizia 2002). The number of LNs largely determines the degree of network connectivity and hence its computational capacity. In the honeybee $\sim 4,000$ LNs outnumber PNs almost fivefold, providing for an exceptionally dense interneuron network (Galizia 2008; Rybak 2012). Despite the obvious importance of the interneuron network, we know surprisingly little about its detailed involvement in sensory computation (Galizia and Rössler 2010, 2008; Nawrot 2012; Rössler and Brill 2013).

For our analyses, we combined independently obtained data sets from in vivo intracellular recordings of olfactory neurons in the honeybee AL. A subset of cells could be identified unambiguously as either LN or PN. We defined a number of electrophysiological response features and used a semisupervised clustering method to identify the combination of features that allowed for the most successful classification of the morphologically identified neurons as either LN or PN. Characteristic differences between all neurons in the PN cluster and those in the LN cluster indicate their differential role in computing the spatio-temporal odor code that is conveyed to central brain structures. 


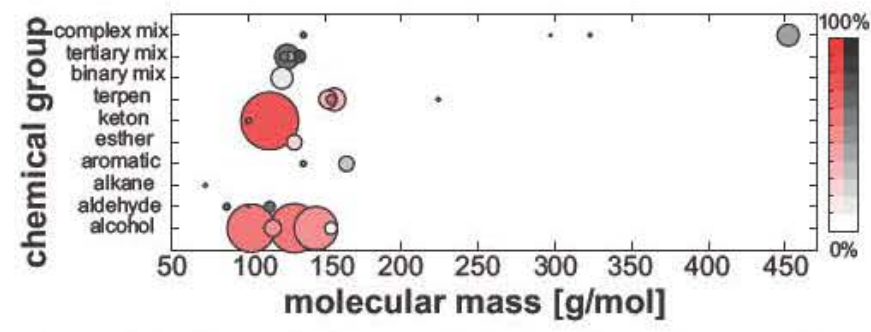

Fig. 1. Overlap in stimulus space between studies. Odors used by the different studies are organized according to their chemical group and molecular weight (MW). Each circle corresponds to one odor. Circle size corresponds to the number of tested cells (1-60), and hue to the percentage of cells that showed a response to that odor. Red color indicates odors, which were used by more than one study; gray, those that were tested only in a single setup. Tested odors and their MW are as follows: alcohol: 6ol (MW 102), 7ol (MW 116), 8ol (MW 130), 9ol (MW 144), Geraniol (MW 154); terpene: Citral (MW 152), Menthol (MW 154), Cineol (MW 156), Linalool (MW 224); aldehyde: 5al (MW 86), 6al (MW 100), 7al (MW 114); ketone: 6on (MW 100), 7on (MW 114); ester. ISO (MW 130); alkane: 5an (MW 72); aromatic: MethylBenzeat (MW 136), Eugenol (MW 164); binary mix: 8ol/ 7on (MW 122); tertiary mix: 9ol/6ol/7on (MW 125), cineol/5al/9al (MW 127), 6one/citral/eugenol (MW 123), 8ol/pepermint/7al (MW 133); complex mix: Limonene (MW 136), Henkel (MW 297), Rose Oil (MW 323), Orange Oil (MW 452).

\section{MATERIALS AND METHODS}

\section{Data Sets}

Analysis of odor-evoked activity patterns was performed on intracellular recordings from $80 \mathrm{AL}$ neurons. The data pool comprised three independently obtained data sets, which were previously published in peer reviewed journals (Galizia and Kimmerle 2004; Krofczik et al. 2008; Meyer and Galizia 2011) as well as one set of data $(n=10)$, which was part of a published dissertation (Meyer 2011). The same recording technique was used in all cases, but stimulus protocols differed in details. To eliminate effects that may be caused by differences in stimulus timing, we cut all trials, irrespective of genuine stimulus duration $(800-2,000 \mathrm{~ms})$ to a length of $500 \mathrm{~ms}$ preand $800 \mathrm{~ms}$ poststimulus onset. The sampled odorant space largely overlapped between studies (Fig. 1). Binary mixtures and tertiary mixtures were only tested in single studies, but were composed from components within the overlapping odorant space. Some odorants as well as complex, natural mixtures were tested in only few neurons. Stimulus concentration was in a biological relevant range between $10^{-1}$ and $10^{-2}$. In all cases, a continuous flow-olfactometer was used for stimulation to reduce mechanical artifacts. Pure air and mineral oil served as control stimuli.

For details of data acquisition and tested odor sets, refer to the original works by Meyer and Galizia (2011), Meyer (2011), Krofczik et al. (2008), and Galizia and Kimmerle (2004). Based on morphological data from post hoc staining, a subset of cells could be identified as PNs $(n=23)$ or LNs $(n=9)$.

\section{Data Preprocessing}

Potent stimuli, i.e., stimuli that evoked responses, were identified for each individual cell by visual inspection. Points in time at which action potentials occurred were detected by thresholding the membrane potential using Spike2 (Cambridge Electronic Design) or custom-written routines in R (www.r-project.org) based on the opensource packages SpikeOMatic (Pouzat et al. 2004) and STAR (Pippow et al. 2009). To describe subthreshold characteristics, we removed all action potentials from the raw signal using a customwritten routine in MatLab (7.10.0, The Mathworks).

\section{Determination of Optimal Feature Set}

Neural responses were analyzed in the response window $\mathrm{W}_{\text {resp }}=$ $[0 \mathrm{~ms}, 800 \mathrm{~ms}]$ following stimulus onset $(t=0 \mathrm{~ms})$, and spontaneous activity was analyzed in the baseline window $\mathrm{W}_{\text {base }}=[-500 \mathrm{~ms}, 0$ $\mathrm{ms}$ ] immediately preceding stimulus onset (Fig. $2 A$ ). We defined a total of nine electrophysiological features that describe different properties of neural response activity. These features were computed such that any effect of stimulus identity is minimized. The computation of each feature is detailed below. Our goal was to find an optimal subset of features that allows separating the two morphological classes of LNs and PNs. This combination of descriptors was found by testing cell type classification for all possible feature combinations in a repeated semisupervised clustering procedure. The core routine of the semisupervised method was identical with the one detailed below for the final clustering result. In brief, the selected combination of descriptors was submitted to principal component analysis (PCA). The number of principal components (PCs) was chosen such that adding another PC did not substantially increase explained variance (elbow-criterion). Clustering was performed on the determined number of PCs, and the number of clusters was fixed to two. We calculated

A
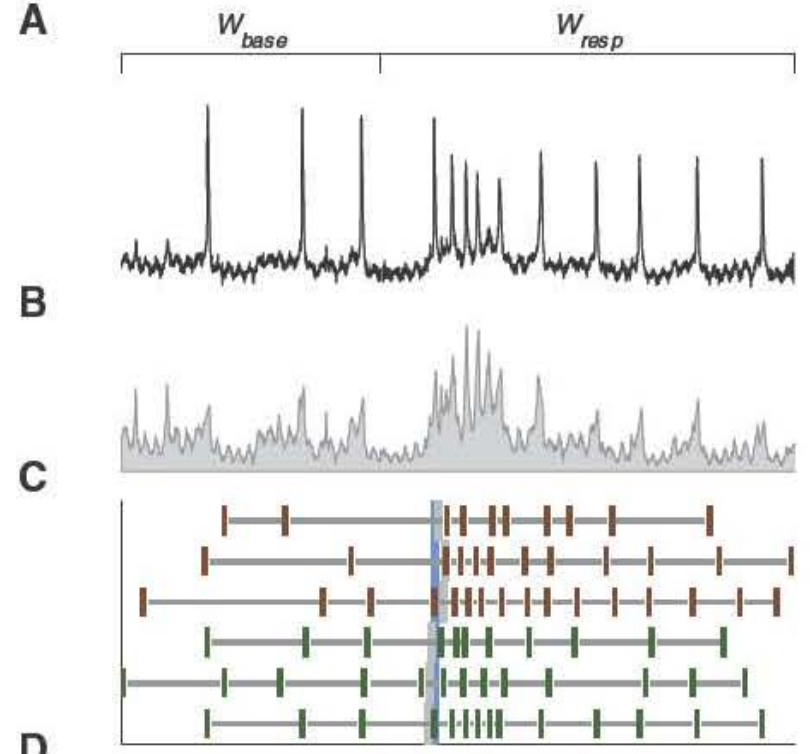

D

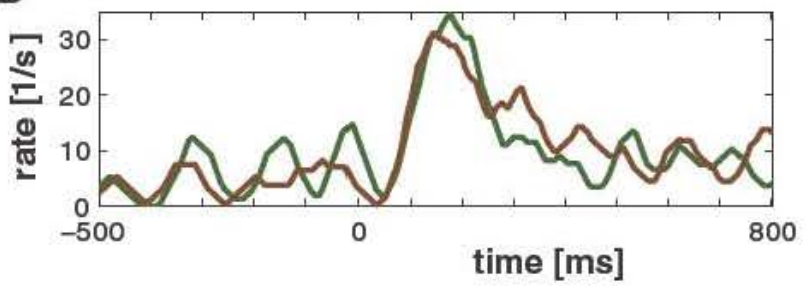

Fig. 2. Estimation of physiological odor response features. $A$ : single trace of the intracellular membrane voltage recorded from one identified local interneuron (LN). $\mathrm{W}_{\text {base }}$ indicates the 500 -ms prestimulus onset interval, which was used to calculate baseline activity. $\mathrm{W}_{\text {resp }}$ indicates the $800-\mathrm{ms}$ interval considered for response analysis. $B$ : squared membrane potential from the trace in $A$ after spikes had been removed (subthreshold activity). The sum of this signal over $\mathrm{W}_{\text {be }}$ results in the baseline power $\mathrm{P}, C$ : to estimate the mean cell latency (blue line), spike-trains were first aligned within repeated odor stimulations (red/green) and subsequently across stimuli. Single-trial latencies are indicated by vertical gray bars. The coefficient of variation of the interspike intervals (CV2) was calculated from consecutive pairs of interspike intervals (horizontal gray bars). $D$ : time-resolved firing rate profiles for two different odor stimuli (red, green). For each stimulus, this is estimated by first pooling all spikes from the aligned single trials and subsequent kernel estimation with an alpha-shaped kernel. For details of physiological response feature estimation, see MATERIALS AND METHODS. 
the separation quality of identified neurons in the two clusters using Matthew's correlation coefficient (Matthews 1975). By this procedure, we identified a subset of five relevant features that yielded the best separation of PNs and LNs. For analysis and visualization of the data, we used Matlab.

\section{Definition of Response Features}

$\Delta R$. Deflection from the baseline firing rate immediately following stimulus application is the most common definition of evoked spiking activity. Rate increase (decrease) is a measure for excitation (inhibition). The time-resolved firing rate profile was estimated based on trial-aligned and trial-averaged spike-trains following the method described in Meier et al. (2008). In brief, first, the derivative of each single trial spike-train of a given cell under stimulation with a particular odor was estimated by convolving the spike-train with an asymmetric Savitzky-Golay filter (Savitzky and Golay 1964) (polynomial order 2, width $300 \mathrm{~ms}$, Welch-windowed). Second, all singletrial derivatives were optimally aligned by maximizing their average pairwise cross correlation (Nawrot et al. 2003) (Fig. 2C). Third, the newly aligned spike-trains were merged. Fourth, the alignment procedure was repeated for the merged spike-trains that resulted from different odors. To estimate the average rate function of the input data, the merged spike-train was normalized by the number of contributing trials and convolved with an asymmetric alpha kernel $k(t)=t \times \exp$ $(-t / \tau)$ (Parzen 1962) (Fig. 2D). $\Delta R$ was then defined as the difference between the highest value of peak firing rate and the minimum rate value encountered in any of the trials, irrespective of the odor. Thus $\Delta R$ estimates the maximal modulation depth of firing rate across time and odors. Optimal kernel width $\tau$ was estimated on the basis of the empirical data by application of a heuristic method detailed in Nawrot et al. (1999).

$R_{\text {base }}$. Spontaneous activity during the prestimulus interval $\mathrm{W}_{\text {base }}$ quantifies a neuron's baseline firing in the absence of a driving stimulus. The average spontaneous rate profile was estimated for each odor as detailed above and subsequently aligned and averaged between odors. Baseline activity was then defined as the mean firing rate within $500 \mathrm{~ms}$ prestimulus.

$L$. $L$ describes the positive time interval between stimulus onset and onset of neural response. Trial-averaged absolute latency and relative trial-to-trial latencies were estimated with one of three methods based on the cell's firing pattern. 1) Latencies with excitatory responses were estimated based on the derivative of the trial-aligned firing rate (Meier et al. 2008; Krofczik et al. 2008). The trial alignment procedure was conducted as described above. By convolution of the summed across-odor spike-train with the same asymmetric SavitskyGolay filter that was used for the alignment procedure, an estimate about the derivative of the cell's average firing rate was obtained. The cell-specific absolute latency was defined as the time point of the first maximum encountered in the derivative (Fig. 2C). 2) Latencies of inhibitory responses were estimated identically but using an inverted Savitsky-Golay filter to detect the maximum of the negative slope. 3) Latencies of cells that had very low spontaneous activity and which responded to stimulation with a membrane depolarization accompanied by one single or very few spikes were estimated based on the pooled original spike-trains and not aligned. Spikes denoting a response were generally well timed. An additional alignment usually introduced faulty shifts as a consequence of the generally low spiking activity. The response latency $(L)$ was thus defined as the peak-time of the rate, which in these conditions essentially resembled the first spike latency. Rate was estimated as detailed above.

To normalize absolute latencies for differences in odor delivery times in the different data sets which arise from differences in the experimental setup, we preceded as follows. At any one time we subtracted the shortest latency within each individual data set from all other latency estimates within the same data set. To avoid zero latency, we added the arbitrary duration of $6 \mathrm{~ms}$ to the $L$ of each cell.
$\Sigma L$. The alignment procedure detailed above returned relative time shifts for each individual trial, indicating the variable latencies (Nawrot et al. 2003). The standard deviation $\Sigma$ of trial-to-trial shifts provides a measure for the across-trial latency variability.

$C V 2$. The coefficient of variation $(\mathrm{CV})$ of the interspike intervals indicates a neuron's spike-time irregularity (Nawrot 2010) (Fig. 2C). The CV2 was introduced to quantify interval dispersion when firing rate is not constant but modulated (Holt et al. 1996; Ponce-Alvarez et al. 2010). It is defined locally as the variance of two consecutive interspike intervals divided by their mean. We first calculated the averaged CV2 for each single trial and then averaged over all trials, irrespective of stimulus type.

$F F$. Fano factor (FF) is an established measure for spike count variability (Nawrot et al. 2008) and defined by the ratio of the across-trial variance and the trial-averaged spike count within $\mathrm{W}_{\text {resp }}$ We computed the FF for each stimulus separately and subsequently averaged across odors.

$P_{\text {base }}$. Spontaneous signal power $\left(\mathrm{P}_{\text {base }}\right)$ of the membrane potential (Fig. $2 B$ ) during the prestimulus interval $\mathrm{W}_{\text {base }}$ quantifies the membrane potential fluctuations in the absence of a driving stimulus. It is computed within each trial as $\mathrm{P}=1 / T \int_{0}^{T}|s(t)|^{2} \mathrm{~d} t$ after removal of action potentials and subsequently averaged across trials.

$P_{\text {evok }}$. Stimulus-related changes in signal power were computed after removal of action potentials as detailed above within each trial. The signal was baseline corrected by subtracting $\mathrm{P}_{\text {base }}$.

$A$. Area values describing de- and hyperpolarization were calculated for each individual trial of a given cell. From these values, the positive extremum and negative extremum were chosen to characterize the cell. For this purpose, the signal was smoothed using a Gaussian kernel (25-ms standard deviation). The area under/above a threshold of average baseline voltage \pm 2 SDs was taken into account.

\section{Cluster Analysis}

Collecting descriptive values to characterize evoked activity results in a multidimensional data space. Several descriptors derive in part from the same origin and may hence be correlated and carry partly redundant information. PCA allows the reduction of a set of possibly correlated variables into a smaller set of uncorrelated variables called PCs (Pearson 1901) that still retain the major information content. Using PCA in the present data set allowed reduction of five descriptors to the first three PCs. These were sufficient to explain $75 \%$ of the underlying variance. Since the original variables differ in the scale on which observations were made, data were normalized using $z$-scores before it was subjected to the PCA algorithm. To explore possible grouping of neurons according to the PCs of their evoked activity characteristics, unsupervised clustering using Ward linkage with Euclidean distances was performed. The incremental method aims to reduce the variance within a cluster by merging data points into groups in a way that their combination gives the least possible increase in the within-group sum of squares (Ward 1963). The distance $d$ between two groups $(r, s)$ is defined as:

$$
d(r, s)=\sqrt{\frac{2 n_{r} n_{s}}{n_{r}+n_{s}}}\left\|\bar{x}_{r}-\bar{x}_{s}\right\|_{2}
$$

where \|\|$_{2}$ denotes the Euclidean distance, $\bar{x}_{r}$ and $\bar{x}_{s}$ are the centroids of clusters $r$ and $s$, respectively, and $n$ refers to the number of elements in each cluster. The algorithm was provided by the Matlab Statistics Toolbox.

To test whether clustering performed on PC input yields information, which allows describing neuron differences in terms of direct measurable characteristics, we performed a Wilcoxon rank sum test on the features between the two clusters. 


\section{RESULTS}

Classification of PNs and LNs Can Be Achieved Based on an Optimal Set of Electrophysiological Response Features

We initially defined 9 distinct measures of electrophysiology to describe the response properties of each of the $80 \mathrm{AL}$ neurons in our data set (see MATERIALS AND METHODS; Table 1). To classify LNs and PNs (Fig. 3A), we applied a semisupervised clustering method based on all possible combinations of electrophysiological features. We evaluated the classification performance based on the separation of morphologically identified LNs and PNs as a measure for model quality (see MATERIALS AND METHODS). By systematic variation of the feature set and of the dimension of the PC space, we found that several subsets of our measures were sufficient to separate identified LNs and PNs significantly above chance level. We aimed at finding that constellation, in which the best classification could be achieved based on a minimal set of input features. The most efficient solution allowed for a correct classification of 29 out of 32 identified neurons, corresponding to a Matthew's correlation coefficient of 0.78 . This optimal solution is based on the first three PCs $(75 \%$ explained variance, Fig. $3 F)$ from a combination of five response features (Fig. 2): $\Delta R, L, \mathrm{CV} 2$ as a local measure of interspike interval variability, trial-by-trial response variability as measured by the FF, and the signal power of the spontaneous subthreshold membrane potential $\left(\mathrm{P}_{\text {base }}\right)$. In an attempt to visualize functional stereotype, we arranged one randomly selected spike-train from each neuron (Fig. 3B) according to their relationship in the cluster tree (Fig. $3 C$ ). Judging from this account, it appears that neurons in the PN cluster have a tendency to display aphasic-tonic response characterized by high rate changes. LN cluster neurons, in comparison, tend to display phasic responses but with much smaller rate changes. Despite this trend, which may be observed in dense spike-histograms, it becomes evident that classification of single spike-trains as observed during an experiment is hard to accomplish. To visualize separation of the PN and LN dominated clusters more clearly, we plotted all cells in the three-dimensional PC space (Fig. 3D). The two clusters largely separate from each other, but do show an area of overlap, in which misclassification is more likely to appear. To further quantify cluster quality, we compared the distribution of distances of individual elements to the cluster centers within and between the clusters (Fig. 3E). Distances within each of the clusters are clearly shorter than between the clusters.

\section{LNs and PNs Differ Significantly in Their Odor Response Features}

We could show that, based on the PCs of five electrophysiological measures, neurons clustered in two groups, one of which is clearly dominated by PNs, the other by LNs (Fig. 3). Hence, all nonidentified neurons in those clusters may be considered as putative PNs and LNs, respectively. Next we asked if this clustering is reflected in significant differences in the input feature space, i.e., the actual odor response measures. Indeed, we found that the PN and the LN dominated clusters differed significantly in each of these measures (Wilcoxon rank sum test, Table 2; Fig. 4A). Neurons in the PN cluster typically showed higher dynamic $\Delta R$ when responding to a stimulus.
This is in good accordance with the observed tendency for phasic-tonic response patterns (Fig. 3B). The responses of LNs typically follow stimulus onset with shorter response latencies than PNs. The difference in median latencies between LNs and PNs is considerable with $65 \mathrm{~ms}$. Interestingly, latencies in both clusters show a broad distribution across neurons. Particularly, response onsets in the subset of identified LNs varies between quartiles by about $200 \mathrm{~ms}$ ( 1 st quartile $=36 \mathrm{~ms}$, 3rd quartile $=$ $235 \mathrm{~ms}$ ). Response onsets in the subset of identified PNs is significantly less variable with an interquartile distance of about $100 \mathrm{~ms}$ (1st quartile $=74 \mathrm{~ms}$, 3rd quartile $170 \mathrm{~ms}$, one-tailed Ansari-Bradley test, $P=0.046$ ). The higher CV2 for neurons allocated to the LN cluster illustrates that these cells are characterized by more irregular or burstlike spike responses, while cells of the PN cluster show more regular response trains. A higher FF indicates responses from PN cluster neurons to be more variable across trials.

Differences in all five features between neurons in the LN and PN cluster transfer to the subset of morphologically identified neurons (Fig. 4B, Table 2). This reassures that electrophysiological characteristics are truly stereotyped properties of LNs and PNs, respectively. Change in response-related firing rate $(\Delta R)$ and CV2 in particular are significantly different $(P<$ $0.05)$, even for the small sample size of identified LNs $(n=9)$ and PNs $(n=23)$. For $L, \mathrm{FF}$, and $\mathrm{P}_{\text {base }}$, differences in median for morphologically identified LNs and PNs are in accordance with the respective differences measured on the basis of the complete set of neurons (Table 2).

\section{DISCUSSION}

Based on intracellular recordings from a mixed neuron population in the honeybee AL, we explored characteristic differences between LNs and PNs. Electrophysiological measures are established means by which neurons are typified if morphological information is unavailable (Ascoli et al. 2008; Connors and Gutnick 1990; Markram et al. 2004). Clustering analyses have been used repeatedly in vertebrates to typify neurons on the basis of morphological and electrophysiological features, and to characterize their specific functional properties within microcircuits (McCormick et al. 1985; Ruigrok et al. 2011; Suzuki and Bekkers 2006, 2011; Wiegand et al. 2011). In our approach, we clustered cells solely based on physiological response measures to separate two morphologically welldescribed classes of LNs and PNs in the honeybee AL. Using the morphological class identity available for a subset of all cells allowed us to assess classification accuracy and to optimize the clustering approach with respect to the number of PCs and the particular combination of features. We found a combination of five out of nine odor response features to be indicative of the morphological cell type. How can we interpret these characteristic physiological differences in a functional context?

\section{PN Properties Are Well Suited to Convey a Combinatorial Rate Code}

A considerable level of spontaneous activity and a strong and odor-specific modulation of the firing rate have been described as characteristic for honeybee PNs, but less typical for LNs in independent comparative studies (Abel et al. 2001; Müller et al. 2002; Sun et al. 1993). Pronounced baseline activity may arise from cell-intrinsic excitability or auto-rhyth- 
Table 1. Individual feature values for all neurons

\begin{tabular}{|c|c|c|c|c|c|c|c|c|c|c|c|c|c|}
\hline Cell ID & $\mathrm{FF}$ & $\mathrm{CV} 2$ & $R_{\text {base }}, \mathrm{Hz}$ & $R_{\text {evok }}, \mathrm{Hz}$ & $L, \mathrm{~ms}$ & $\Sigma L, \mathrm{~ms}$ & $\mathrm{P}_{\text {base }}, \mathrm{V}^{2}$ & $\mathrm{P}_{\mathrm{evok}}, \mathrm{V}^{2}$ & $A$ & Morphology & Subgroup & Glomerulus & Paper \\
\hline 01072009a & 0.159 & 0.368 & 4.475 & 12.921 & 158 & 41 & 0.078 & 1.504 & 0.040 & & & & Meyer \\
\hline 01072009b & 0.071 & 0.333 & 3.516 & 9.389 & 143 & 33 & 0.249 & 1.043 & 0.016 & & & & Meyer \\
\hline 01092009a & 0.737 & 0.733 & 0.662 & 11.729 & 117 & 9 & 0.095 & 1.710 & 0.050 & & & & Meyer \\
\hline $01092009 \mathrm{~b}$ & 3.483 & 0.679 & 1.676 & 29.198 & 72 & 22 & 0.217 & 1.629 & 0.216 & & & & Meyer \\
\hline 02092009a & 0.200 & 0.318 & 0.589 & 10.397 & 118 & 28 & 0.170 & 1.524 & 0.169 & & & & Meyer \\
\hline $02092009 b$ & 0.469 & 0.750 & 4.783 & 14.178 & 142 & 30 & 0.370 & 0.493 & 0.340 & PN & ml-APT & $\mathrm{T} 1-43$ & Meyer \\
\hline 3032009 & 0.022 & 0.354 & 4.710 & 11.054 & 92 & 25 & 0.235 & 1.060 & 0.000 & & & & Meyer \\
\hline 4062008 & 1.884 & 0.402 & 5.377 & 51.569 & 77 & 13 & 0.287 & 0.987 & 0.000 & & & & \\
\hline 7062009 & 0.033 & 0.644 & 1.764 & 13.547 & 171 & 17 & 0.201 & 1.423 & 0.304 & & & & Meyer \\
\hline 8072009 & 1.409 & 0.698 & 0.371 & 10.878 & 88 & 23 & 0.179 & 1.927 & 0.179 & & & & Meyer \\
\hline 8102009 & 0.557 & 0.689 & 0.518 & 8.549 & 169 & 29 & 0.155 & 1.549 & 0.113 & & & & Meyer \\
\hline 9092009 & 0.677 & 0.458 & 1.840 & 47.809 & 80 & 9 & 0.189 & 1.629 & 0.130 & & & & Meyer \\
\hline 10062009 & 1.335 & 0.430 & 2.147 & 32.229 & 150 & 19 & 0.276 & 1.719 & 0.159 & & & & Meyer \\
\hline 11022009 & 0.017 & 0.116 & 14.836 & 15.704 & 81 & 4 & 0.139 & 2.207 & 0.242 & & & & \\
\hline 11122008 & 1.808 & 0.584 & 2.752 & 8.442 & 166 & 13 & 0.210 & 1.130 & 0.055 & & & & \\
\hline 13012009 & 0.143 & 0.353 & 2.320 & 8.047 & 98 & 20 & 0.258 & 1.181 & 0.104 & & & & \\
\hline 14102009 & 0.127 & 0.786 & 0.783 & 8.594 & 127 & 22 & 0.103 & 1.373 & 0.026 & & & & Meyer \\
\hline 15042009 & 0.560 & 0.263 & 0.993 & 8.639 & 64 & 14 & 0.212 & 1.250 & 0.105 & $\mathrm{LN}$ & hetero & T1-19 & Meyer \\
\hline 16092009 & 0.063 & 0.560 & 1.675 & 22.613 & 69 & 6 & 0.361 & 1.246 & 0.151 & & & & Meyer \\
\hline 18022009 & 0.623 & 0.481 & 1.294 & 14.946 & 100 & 13 & 0.178 & 1.626 & 0.182 & $\mathrm{LN}$ & homo & $\mathrm{T} 1$ & \\
\hline 22042009 & 0.154 & 0.497 & 1.333 & 9.234 & 63 & 7 & 0.159 & 1.830 & 0.177 & & & & Meyer \\
\hline 22092009 & 0.012 & 0.131 & 6.823 & 14.508 & 86 & 27 & 0.131 & 2.354 & 0.231 & & & & Meyer \\
\hline $22102008 \mathrm{a}$ & 0.250 & 0.713 & 2.832 & 9.083 & 103 & 0 & 0.237 & 0.883 & 0.157 & & & & \\
\hline $22102008 b$ & 1.886 & 0.549 & 2.641 & 65.331 & 122 & 55 & 0.126 & 2.218 & 0.215 & & & & \\
\hline $26082009 a$ & 1.075 & 0.395 & 0.296 & 17.876 & 108 & 13 & 0.084 & 1.291 & 0.086 & & & & Meyer \\
\hline $26082009 b$ & 0.037 & 0.295 & 2.166 & 9.489 & 121 & 32 & 0.146 & 1.035 & 0.000 & & & & Meyer \\
\hline $27012009 a$ & 1.275 & 0.968 & 0.833 & 7.167 & 161 & 26 & 0.188 & 0.751 & 0.181 & & & & \\
\hline $27012009 b$ & 0.028 & 0.171 & 10.400 & 14.454 & 142 & 61 & 0.100 & 4.854 & 0.296 & & & & \\
\hline $30062009 a$ & 0.421 & 0.795 & 1.154 & 10.560 & 99 & 17 & 0.095 & 1.930 & 0.264 & & & & Meyer \\
\hline $30062009 b$ & 0.040 & 0.268 & 14.502 & 17.864 & 61 & 39 & 0.071 & 4.225 & 0.247 & & & & Meyer \\
\hline 30092009 & 1.324 & 0.727 & 2.603 & 14.726 & 79 & 32 & 0.202 & 1.571 & 0.047 & & & & \\
\hline 000307_2 & 20.026 & 0.109 & 0.000 & 49.705 & 223 & 46 & 0.009 & 44.131 & 0.467 & PN & 1-APT & $\mathrm{T} 1-36$ & Galizia \\
\hline 000317_a & 2.104 & 0.376 & 12.729 & 11.629 & 212 & 17 & 0.385 & 1.009 & 0.053 & PN & 1-APT & $\mathrm{T} 1-35$ & Galizia \\
\hline 000317_aneg & 10.928 & 0.323 & 1.176 & 5.041 & 284 & 56 & 0.297 & 1.592 & 0.306 & PN & 1-APT & $\mathrm{T} 1-35$ & Galizia \\
\hline 000317 b & 2.469 & 0.803 & 2.293 & 8.885 & 48 & 17 & 0.328 & 0.914 & 0.147 & & & & Galizia \\
\hline 000406_1 & 3.219 & 0.302 & 1.200 & 8.411 & 165 & 16 & 0.118 & 2.404 & 0.208 & PN & 1-APT & $\mathrm{T} 1-38$ & Galizia \\
\hline 000406_2 & 7.375 & 0.601 & 0.554 & 1.530 & 231 & 48 & 0.119 & 5.599 & 0.315 & & & & Galizia \\
\hline 000414_1 & 0.646 & 0.298 & 0.897 & 3.857 & 279 & 53 & 0.153 & 1.097 & 0.108 & $\mathrm{LN}$ & hetero & T1-29 & Galizia \\
\hline 000418_3 & 0.422 & 0.336 & 7.127 & 2.621 & 296 & 33 & 0.080 & 1.254 & 0.000 & $\mathrm{LN}$ & hetero & $\mathrm{T} 1-51$ & Galizia \\
\hline 000426_1 & 1.293 & 0.574 & 0.135 & 59.965 & 130 & 44 & 0.131 & 8.900 & 0.296 & LN & hetero & T1-36 & Galizia \\
\hline 000504_1 & 1.115 & 0.588 & 0.333 & 7.485 & 171 & 21 & 0.055 & 3.545 & 0.273 & $\mathrm{LN}$ & hetero & $\mathrm{T} 1-12$ & Galizia \\
\hline $01092005 \mathrm{a}$ & 10.685 & 0.191 & 0.185 & 136.613 & 343 & 69 & 0.210 & 1.408 & 0.188 & & & & Krofczik \\
\hline $01092005 b$ & 0.215 & 0.362 & 0.626 & 100.171 & 352 & 49 & 0.145 & 1.502 & 0.223 & & & & Krofczik \\
\hline 02092005a & 0.945 & 0.102 & 2.981 & 84.634 & 260 & 16 & 0.183 & 1.443 & 0.214 & LN & $?$ & $?$ & Krofczik \\
\hline 02092005b & 2.390 & 0.309 & 0.877 & 84.365 & 257 & 21 & 0.194 & 1.523 & 0.159 & $\mathrm{PN}$ & 1-APT & T1-33 & Krofczik \\
\hline $03052005 \mathrm{a}$ & 4.012 & 0.336 & 1.777 & 64.066 & 368 & 66 & 0.204 & 1.211 & 0.147 & & & & Krofczik \\
\hline $03052005 b$ & 3.662 & 0.376 & 1.711 & 87.250 & 342 & 51 & 0.294 & 1.086 & 0.225 & & & & Krofczik \\
\hline $04072006 a$ & 0.007 & 0.215 & 0.000 & 129.422 & 220 & 0 & 0.552 & 0.799 & 0.469 & PN & 1-APT & $\mathrm{T} 1-42$ & Krofczik \\
\hline 05012006a & 0.176 & 0.360 & 0.976 & 32.876 & 228 & 26 & 0.206 & 1.276 & 0.105 & & & & Krofczik \\
\hline $05012006 \mathrm{~b}$ & 0.775 & 0.352 & 0.556 & 12.802 & 261 & 36 & 0.194 & 1.318 & 0.197 & & & & Krofczik \\
\hline 05052006a & 1.349 & 0.802 & 0.601 & 3.709 & 290 & 31 & 0.050 & 2.684 & 0.204 & $\mathrm{LN}$ & $?$ & $?$ & Krofczik \\
\hline $08012004 a$ & 1.259 & 0.284 & 1.033 & 92.394 & 320 & 60 & 0.150 & 1.617 & 0.140 & & & & Krofczik \\
\hline 08122005a & 1.334 & 0.115 & 0.000 & 147.690 & 303 & 36 & 0.031 & 7.650 & 0.374 & PN & m-APT & T2-06 & Krofczik \\
\hline $10022005 b$ & 6.205 & 0.054 & 0.948 & 86.905 & 343 & 19 & 0.057 & 2.039 & 0.271 & PN & $\mathrm{m}$-APT & $\mathrm{T} 2-02$ & Krofczik \\
\hline $10062006 \mathrm{a}$ & 0.106 & 0.107 & 0.000 & 13.037 & 288 & 20 & 0.291 & 1.689 & 0.283 & $\mathrm{PN}$ & m-APT & T3-45 & Krofczik \\
\hline $10062006 \mathrm{~b}$ & 0.227 & 0.176 & 0.000 & 28.021 & 273 & 14 & 0.608 & 0.805 & 0.462 & PN & $\mathrm{m}$-APT & T3-18 & Krofczik \\
\hline $10092004 a$ & 3.478 & 0.520 & 0.000 & 12.137 & 519 & 27 & 0.053 & 3.790 & 0.261 & $\mathrm{LN}$ & $?$ & $?$ & Krofczik \\
\hline $10112005 \mathrm{a}$ & 1.772 & 0.603 & 0.138 & 71.071 & 305 & 32 & 0.273 & 1.320 & 0.139 & & & & Krofczik \\
\hline $11012005 \mathrm{a}$ & 5.388 & 0.741 & 0.304 & 90.607 & 235 & 35 & 0.141 & 1.612 & 0.130 & $\mathrm{PN}$ & m-APT & $\mathrm{T} 2-03$ & Krofczik \\
\hline $11062006 a$ & 1.338 & 0.355 & 0.000 & 14.530 & 542 & 17 & 0.261 & 1.029 & 0.156 & $\mathrm{PN}$ & m-APT & $?$ & Krofczik \\
\hline $11062006 b$ & 1.785 & 0.547 & 2.869 & 32.724 & 247 & 44 & 0.394 & 0.805 & 0.283 & & & & Krofczik \\
\hline $11062006 \mathrm{c}$ & 2.667 & 0.350 & 3.860 & 7.263 & 346 & 73 & 0.254 & 1.078 & 0.122 & & & & Krofczik \\
\hline $14032006 a$ & 2.957 & 0.071 & 0.000 & 28.267 & 360 & 29 & 0.146 & 1.458 & 0.211 & $\mathrm{PN}$ & m-APT & T3-16 & Krofczik \\
\hline $14092004 a$ & 5.206 & 0.174 & 0.000 & 43.714 & 393 & 43 & 0.137 & 2.139 & 0.247 & $\mathrm{PN}$ & 1-APT & T1-39 & Krofczik \\
\hline $15062006 b$ & 4.512 & 0.258 & 0.000 & 10.806 & 362 & 66 & 0.316 & 0.840 & 0.190 & PN & m-APT & T3-31 & Krofczik \\
\hline $15092004 \mathrm{a}$ & 0.690 & 0.115 & 0.000 & 64.864 & 502 & 41 & 0.209 & 1.277 & 0.155 & $\mathrm{PN}$ & 1-APT & T1-09 & Krofczik \\
\hline $16062006 b$ & 3.470 & 0.151 & 0.667 & 135.654 & 277 & 42 & 0.243 & 1.196 & 0.155 & & & & Krofczik \\
\hline $18042005 a$ & 1.315 & 0.875 & 0.000 & 52.308 & 370 & 92 & 0.107 & 2.088 & 0.215 & & & & Krofczik \\
\hline
\end{tabular}


Table 1.-Continued

\begin{tabular}{|c|c|c|c|c|c|c|c|c|c|c|c|c|c|}
\hline Cell ID & FF & $\mathrm{CV} 2$ & $R_{\text {base, }} \mathrm{Hz}$ & $R_{\text {evolk }}, \mathrm{Hz}$ & $L, \mathrm{~ms}$ & $\mathbf{\Sigma} L, \mathrm{~ms}$ & $P_{\text {base, }} V^{2}$ & $P_{\text {evok }}, V^{2}$ & $A$ & Morphology & Subgroup & Glomerulus & Paper \\
\hline $20102005 a$ & 12.843 & 0.072 & 0.000 & 139.517 & 302 & 22 & 0.062 & 5.300 & 0.389 & & & & Krofczik \\
\hline $25062006 a$ & 0.466 & 0.399 & 0.329 & 66.701 & 309 & 56 & 0.286 & 1.004 & 0.173 & PN & I-APT & $\mathrm{T} 1-22$ & Krofczik \\
\hline $27062006 a$ & 0.611 & 0.383 & 2.704 & 82.978 & 341 & 20 & 0.275 & 1.058 & 0.256 & & & & Krofczik \\
\hline $27062006 \mathrm{~b}$ & 2.799 & 0.620 & 3.536 & 146.331 & 381 & 43 & 0.200 & 1.092 & 0.157 & & & & Krofczik \\
\hline $28052006 \mathrm{a}$ & 4.793 & 0.236 & 3.483 & 6.687 & 376 & 23 & 0.531 & 0.920 & 0.116 & PN & $\mathrm{m}-\mathrm{APT}$ & T3-64 & Krofczik \\
\hline $28062006 \mathrm{a}$ & 3.237 & 0.408 & 0.651 & 32.724 & 351 & 42 & 0.264 & 0.906 & 0.092 & PN & $\mathrm{m}$-APT & T3-09 & Krofczik \\
\hline 990924_2 & 0.600 & 0.300 & 0.000 & 33.051 & 207 & 173 & 0.309 & 1.038 & 0.074 & & & & Galizia \\
\hline $991103 \_1$ & 9.558 & 0.270 & 6.355 & 7.171 & 146 & 29 & 0.318 & 1.196 & 0.113 & & & & Galizia \\
\hline 991109_1 & 19.686 & 0.127 & 0.489 & 10.399 & 208 & 10 & 0.220 & 1.541 & 0.141 & & & & Galizia \\
\hline Anjal & 25.026 & 0.171 & 1.111 & 89.310 & 276 & 13 & 0.140 & 1.464 & 0.129 & PN & m-APT & T3-09 & Krofczik \\
\hline Anja4 & 0.866 & 0.441 & 2.055 & 44.239 & 362 & 61 & 0.322 & 1.094 & 0.299 & PN & $\mathrm{m}$-APT & T3-68 & Krofczik \\
\hline Backpack11d & 15.693 & 0.196 & 0.000 & 52.329 & 384 & 334 & 0.169 & 1.167 & 0.111 & PN & $\mathrm{m}-\mathrm{APT}$ & T3-56 & Krofczik \\
\hline
\end{tabular}

$\mathrm{LN}$, local interneuron; PN, projection neuron; FF, Fano factor; CV2, coefficient of variation of the interspike intervals; $R_{\text {base }}$, spontaneous activity during the prestimulus interval; $R_{\text {evok }}$, evoked rate; $L$, positive time interval between stimulus onset and onset of neural response; $\Sigma L$, standard deviation of trial-to-trial shifts; $\mathrm{P}_{\text {bnse }}$, baseline power; $\mathrm{P}_{\text {evok }}$, stimulus-related changes in signal power; $A$, area values. Where available, morphological subgroups and innervated glomeruli are indicated. For hetero LNs and 1-ml PN, only the most strongly innervated glomerulus is indicated. For the one identified homo LN, the area corresponding to the innervation by the sensory input (T1-T4) is given. Missing information about morphologically identified neurons is indicated by question marks and arises from low staining quality or ambiguous documentation. The right-most column indicates the original publication in which the electrophysiological data was published: Meyer et al. (2012); Galizia and Kimmerle (2004); Krofczik et al. (2008).

mic activity in the absence of input, or from ongoing network input (Llinas 1988). Baseline activity in AL neurons was recently shown to depend on continuing OSN input even in the absence of overt stimuli and not on auto rhythm (Joseph et al. 2012). PNs form numerous synapses with both LNs and a large number of converging OSNs (Distler and Boeckh 1997; Galizia 2008). During odor stimulation, PNs are the object of strong afferent OSN input and recurrent local network input. According to our analysis, PNs expressed prominent rate modulations (Fig. 4), with typical peak rates in the order of

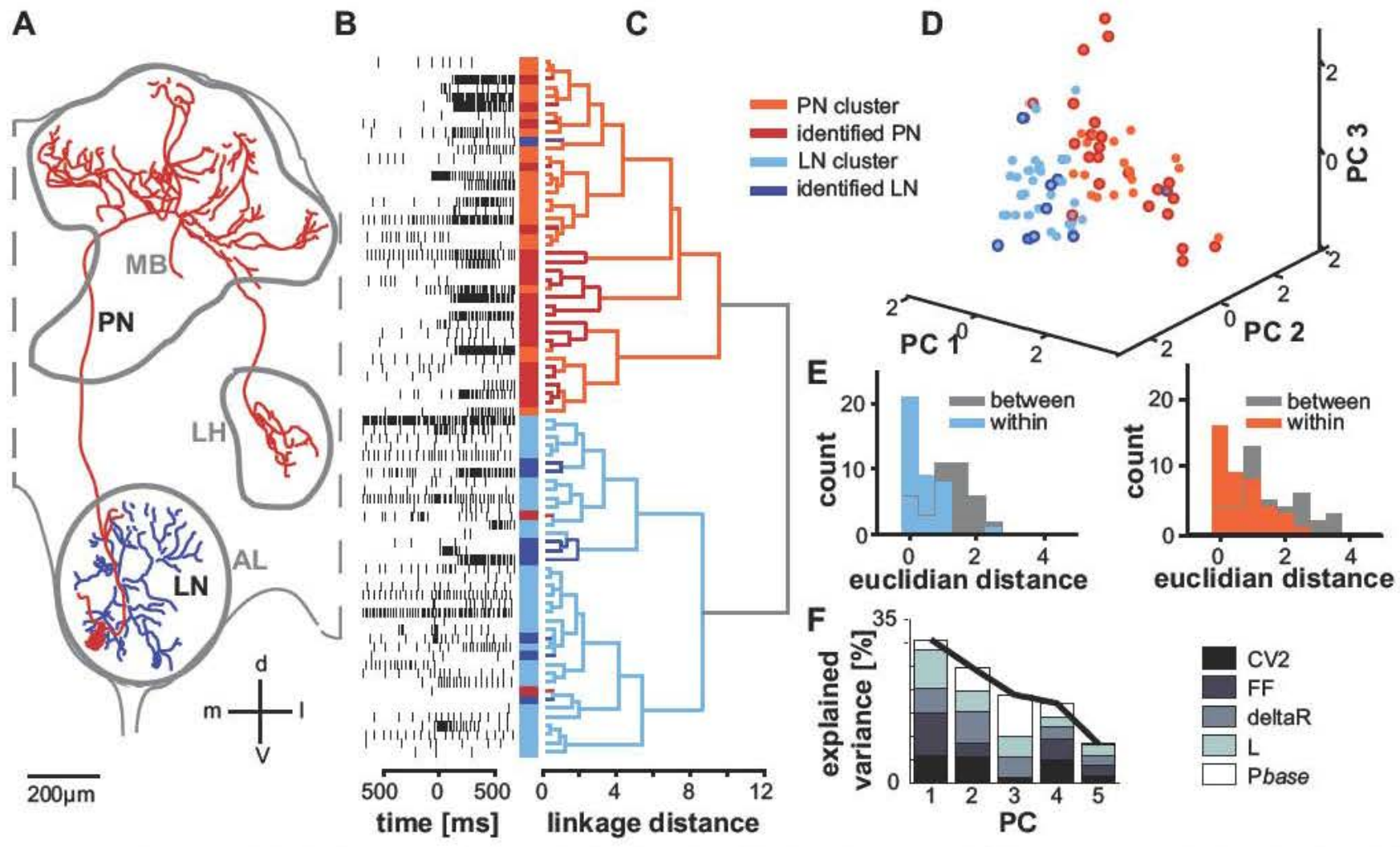

Fig. 3. Classification of antennal lobe (AL) neurons based on physiological response features. $A$ : morphological reconstructions of one projection neuron (PN; dark red) and one LN (dark blue) contained in the analyzed data set. MB, mushroom body; LH, lateral horn. $B$ : exemplary spike-trains (left) randomly selected to illustrate each single neuron's activity. $C$ : based on $\Delta R$ (difference between the highest value of peak firing rate and the minimum rate value encountered in any of the trials), $L$ (positive time interval between stimulus onset and onset of neural response), CV2, Fano factor (FF), and $P_{\text {base }}$ identified PNs (dark red) and identified LNs (dark blue) group into a PN-dominated cluster (light red) and a LN-dominated cluster (light blue). D: scatter plot of PN and LN cluster in three-dimensional principal component (PC) space. Data points corresponding to morphologically identified PNs/LNs are marked in dark red (PNs) and dark blue (LNs). $E$ : distribution of distance from individual data points to cluster centers within and between clusters. $F$ : bar plot illustrating the contribution of the underlying descriptors to each PC. The overlaying black line is the scree plot based on which number of PCs for clustering was chosen. 
Table 2. Median values of physiological response features

\begin{tabular}{lcccccc}
\hline \hline & PN & LN & \multicolumn{1}{c}{$P$} & PN & LN & $P$ \\
\hline$n$ & 41 & 39 & & 23 & 9 & \\
$\Delta R, \mathrm{~Hz}$ & 60 & 11 & $<0.001$ & 43.7 & 8.6 & $<0.01$ \\
$L, \mathrm{~ms}$ & 127 & 63 & $<0.01$ & 137 & 76 & 0.5 \\
$\mathrm{CV} 2$ & 0.3 & 0.52 & $<0.001$ & 0.236 & 0.48 & $<0.05$ \\
$\mathrm{FF}$ & 2.1 & 0.56 & $<0.001$ & 2.96 & 0.94 & 0.12 \\
$\mathrm{P}_{\text {base }}, \mathrm{V}^{2}$ & 0.21 & 0.16 & $<0.05$ & 0.261 & 0.15 & 0.1 \\
\hline
\end{tabular}

$n$, No. of cells. $\Delta R$, difference between the highest value of peak firing rate and the minimum rate value encountered in any of the trials. Columns 1 and 2 show medians of cluster populations; columns 4 and 5 show medians for identified cell populations. $P$ indicates $P$ values (Wilcoxon rank sum test) for difference in median of the corresponding PN and LN populations.

$50-100 \mathrm{~Hz}$. The PN population is thus well suited to project a spatio-temporal rate code to the higher brain centers. Evidence for the existence and behavioral relevance of a combinatorial odor rate code in the PN ensemble has been provided by a number of recent extracellular single-unit recordings (e.g., Brill et al. 2012; Strube-Bloss et al. 2012).

\section{Irregular Spiking and Short Latencies Reflect the Modulatory Function of LNS}

The LN network provides the substrate for mediating a nonlinear transformation between AL input and output in flies and bees (Bhandawat et al. 2007; Meyer and Galizia 2011; Ng et al. 2002; Olsen and Wilson 2008; Sachse et al. 2006; Schmuker 2012). A prerequisite is the widely ramified LN morphology that interconnects many different glomeruli, integrating information from different genetic receptor types. The high CV2 of LNs (Fig. 4, Table 1) likely is a physiological reflection of this intertwined connectivity. Spike time irregu- larity arises from two events: when inhibitory input counteracts excitatory input (Nawrot et al. 2008; Shadlen and Newsome 1998; Stevens and Zador 1998; Vreeswijk and Sompolinsky 1996), or when the excitatory inputs arrive in an irregular fashion, e.g., through integration of inputs with different spiketrain statistics (Farkhooi et al. 2011; Renart et al. 2010), and output irregularity is particularly high when both conditions apply (Bures 2012). Irregular LN output is likely a consequence of heterogeneous input from both excitatory (OSNs and PNs) and inhibitory (LNs) sources (Galizia and Rybak 2010; Malun 1991). In addition, the superposition of inputs from several coactivated glomeruli likely makes excitatory input irregular.

A striking result of our analysis is the faster response time of LNs with a median $L$ of only $\sim 60$ ms compared with $\sim 120 \mathrm{~ms}$ for PNs (Table 2). Fast LN responses coincide with the previous observation of an equally fast reduction of the membrane potential in single PNs (Krofczik et al. 2008) and indicate that LNs can efficiently modulate PN output through fast lateral inhibition. The distribution of individual latencies is rather broad in both neuron populations (Fig. 4). Single PNs can respond much faster than the population average. This observation is interesting in light of the recent findings by StrubeBloss et al. (2012) that AL neurons responded, on average, later to odor stimulation than mushroom body output neurons, which are situated two synapses downstream of PNs. Meyer and Galizia (2011) tested responses of AL neurons to a mixture with two components. They found elemental neurons that showed fast responses dominated by, and temporally locked to, the dominant mixture component. In contrast, configural neurons that represented the novel mixture quality showed longer response latencies. Together, this may indicate that a fast

A
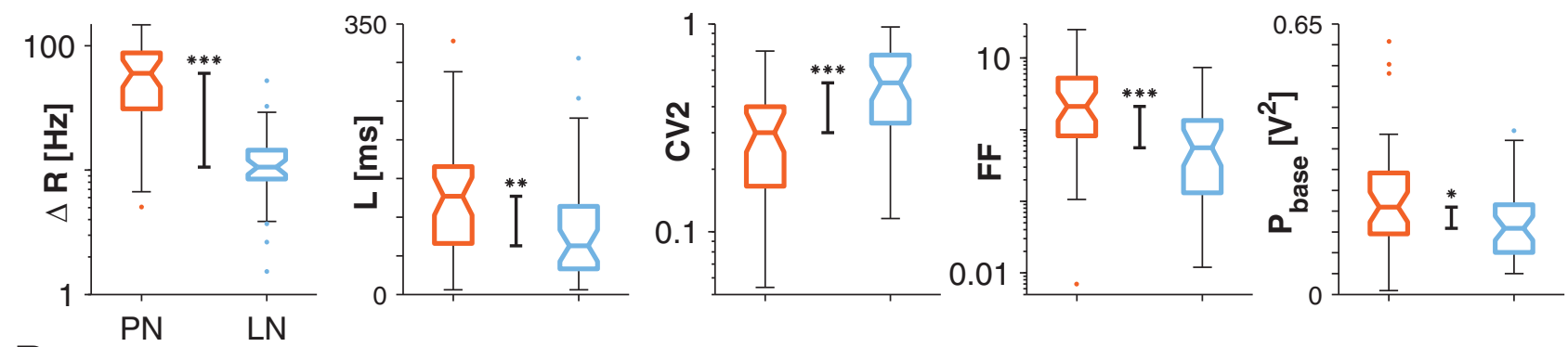

B
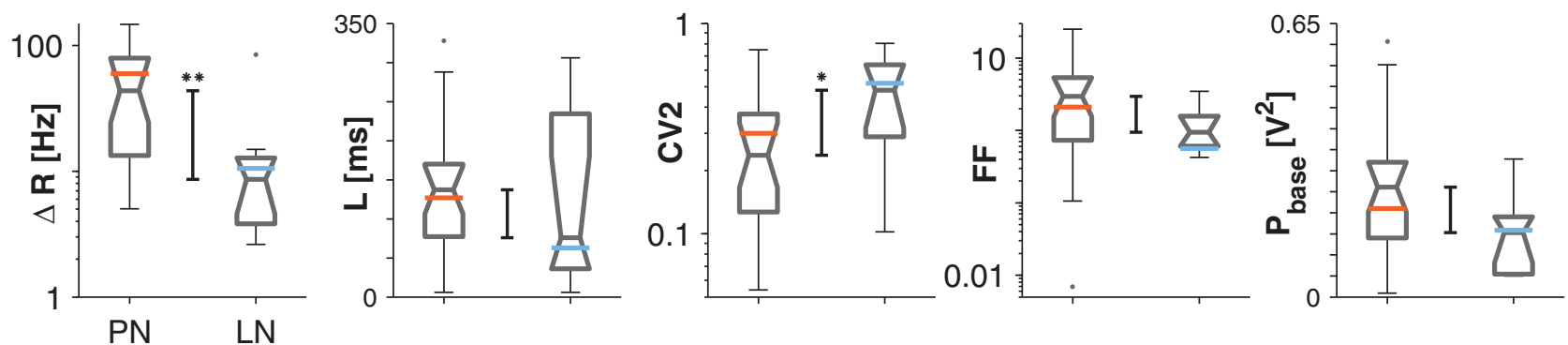

Fig. 4. LN and PN differences in physiological response features. A: box-plots illustrate the distribution of feature values for cells in the PN (light red) and in the LN dominated cluster (light blue) for the set of 5 optimal features, as indicated. The two cell populations differ significantly in all 5 features (Wilcoxon rank sum test; $* P=0.05, * * P=0.01, * * * P=0.001)$. $B$ : box plot of feature values for the subpopulations of morphologically identified PNs $(n=23)$ and LNs $(n=9)$. The two cell populations differed significantly in the case of $\Delta R$ and CV2 (Wilcoxon rank sum test; $* P=0.05, * * P=0.01$ ). For the remaining features, the differences and medians are consistent with those of the cluster populations in $A$. Light red and light blue horizontal bars indicate medians of the populations of clustered neurons in $A$. Note that $y$-axes for $\Delta R, \mathrm{CV} 2$, and FF are scaled logarithmically. 
population of uniglomerular PNs carries an initial rapid odor code. Recurrent projections from the mushroom body to the AL (Hu et al. 2010) could modulate a secondary delayed odor code (Strube-Bloss et al. 2012). In line with this idea, resent results indicate that different families of PNs may exhibit different response latencies (Brill et al. 2013; Rössler and Brill 2013). It has been suggested that the early phasic stimulus response component establishes a latency code of odor identity in the insect (Brill et al. 2012; Krofczik et al. 2008; Kuebler et al. 2011), which might be required for rapid behavioral action. A late and persistent odor code might support the refined percept of the stimulus environment, e.g., mixture composition and concentration of individual elements (Fernandez et al. 2009; Strube-Bloss et al. 2012), and it might underlie the formation of associations.

\section{Properties of AL Neurons Differ Between Species}

Throughout species, the AL is organized in a glomerular fashion and built from the same elements: OSNs, PNs, and LNs. However, numbers and wiring of these constituents differs vastly between species. As a consequence, PNs and LNs may well exhibit different physiological properties in different species. The AL of the Tobacco Hornworm Manduca sexta has regular spiking LNs and shows irregular, burstlike activity in PNs (Lei et al. 2011), opposite to our findings. In Drosophila, populations of both regular and irregular spiking LNs have been described (Chou et al. 2011; Seki et al. 2010). In the cockroach, neurons were identified that produce sodium spikes (Husch et al. 2009). In the locust, only nonspiking interneurons were found so far (Laurent 1993). An explanation for these physiological variations might be found in the species-specific architecture. About 160 glomeruli in the honeybee AL are connected with $\sim 4,000$ LNs (Withöft 1967) but give output via only 800-900 PNs (Rybak 2012). Honeybee LNs innervate subareas of glomeruli in which OSN input is concentrated, as well as subareas in which PN neurites dominate (Fonta et al. 1993), and LNs are likely to form inter- as well as intraglomerular connections (Meyer and Galizia 2011). In other prominent insect models for olfaction, LNs are less numerous than PNs, and the overall degree of connectivity is much smaller [Drosophila: <50 glomeruli (Stocker 1994), 150-200 PNs (Stocker 1997), 100 LNs (Ng et al. 2007); locust: 830 PNs (Leitch and Laurent 1996), 300 LNs (Anton and Homberg 1999); moth: $\sim 60$ glomeruli (Sanes and Hildebrand 1976b), 740 PNs, 360 LNs (Homberg 1988)]. Naturally, these differences in architecture are not only reflected in physiological properties of single neurons, but impact the entire network function at the level of odor and odor mixture encoding, which seems necessary for the species-specific adaption to environmental constraints (Martin et al. 2011).

\section{The Diversity of AL Neurons Within Species}

LNs and PNs establish two anatomically and morphologically well-defined classes of AL neurons. However, both display considerable within-class diversity. In some species, PNs subdivide in morphological subgroups (Galizia and Rössler 2010). In most hymenoptera, including the honeybee, PNs subdivide into three morphological families (Rössler and Zube 2011). LNs can show various different morphologies within a species (Chou et al. 2010; Christensen et al. 1993; Dacks et al.
2010; Flanagan and Mercer 1989; Fonta et al. 1993; Seki and Kanzaki 2008; Seki et al. 2010; Stocker et al. 1990). In the honeybee, so-called homogeneous and heterogeneous LNs represent two major subgroups. However, even morphologically similar LNs may be further differentiated according to, for instance, their histochemistry (Chou et al. 2010; Dacks et al. 2010; Kreissl et al. 2010; Nässel and Homberg 2006; Ng et al. 2007; Schäfer and Bicker 1986). The existence of different families is supported by the diversity of LN physiology (Chou et al. 2011; Husch et al. 2009; Meyer and Galizia 2011; Sachse et al. 2003; Seki et al. 2011) that finds expression in the variances of individual response properties within the LN group of our data set (Fig. 4) and explains why we could not achieve 100\% accuracy of classification (Fig. 3). In future work it will be desirable to extend the present approach to extract communal features of known subgroups such as homo and hetero LNs or PN families. Application to a large data set of extracellular recordings from two types of uniglomerular PNs (Brill et al. 2013) show that this approach is transferable to extracellular spike-train data (Meyer et al. 2012). While our current analysis still provides a limited picture of honeybee LN and PN physiology, it provides for the first time systematic differences of their response physiology. Such detailed knowledge is essential to foster realistic models of neural computation that can explain the complex spatial and temporal processing of peripheral olfactory information in the primary olfactory center.

\section{ACKNOWLEDGMENTS}

We are grateful to Randolf Menzel, Sabine Krofczik, and Bernd Kimmerle for providing data sets for reanalysis in the present paper. We thank Jürgen Rybak for assistance with the morphological data, and Michael Schmuker and Jan Sölter for methodological consultancy.

\section{GRANTS}

Generous funding was received from the German Federal Ministry of Education and Research (BMBF) within the project Bernstein Focus Neural Basis of Learning-Insect Inspired Robots (grant no. 01GQ0941).

\section{DISCLOSURES}

No conflicts of interest, financial or otherwise, are declared by the author(s).

\section{AUTHOR CONTRIBUTIONS}

Author contributions: A.M., C.G.G., and M.P.N. conception and design of research; A.M. and C.G.G. performed experiments; A.M. and M.P.N. analyzed data; A.M. and M.P.N. interpreted results of experiments; A.M. and M.P.N. prepared figures; A.M. and M.P.N. drafted manuscript; A.M., C.G.G., and M.P.N. edited and revised manuscript; A.M., C.G.G., and M.P.N. approved final version of manuscript.

\section{REFERENCES}

Abraham NM, Spors H, Carleton A, Margrie TW, Kuner T, Schaefer AT. Maintaining accuracy at the expense of speed: stimulus similarity defines odor discrimination time in mice. Neuron 44: 865-876, 2004.

Anton S, Homberg U. Antennal lobe structure. In: Insect Olfaction, edited by Hanson B. New York: Springer, 1999, p. 97-124.

Ascoli GA, Alonso-Nanclares L, Anderson SA, Barrionuevo G, BenavidesPiccione R, Burkhalter A. Petilla terminology: nomenclature of features of GABAergic interneurons of the cerebral cortex. Nat Rev Neurosci 9: 557-568, 2008. 
Bathellier B, Buhl DL, Accolla R, Carleton A. Dynamic ensemble odor coding in the mammalian olfactory bulb: sensory information at different timescales. Neuron 57: 586-589, 2008.

Bazhenov M, Stopfer M, Rabinovich M, Abarbanel HD, Sejnowski TJ, Laurent G. Model of cellular and network mechanisms for odor-evoked temporal patterning in the locust antennal lobe. Neuron 30: 569-581, 2001

Bhandawat V, Olsen SR, Gouwens NW, Schlief ML, Wilson RI. Sensory processing in the Drosophila antennal lobe increases reliability and separability of ensemble odor representation. Nat Neurosci 10: 1474-1482, 2007.

Brill MF, Rosenbaum T, Reus I, Kleineidam CJ, Nawrot MP, Rössler W. Parallel processing via a dual olfactory pathway in the honeybee. $J$ Neurosci 33: 2443-2456, 2013.

Bures Z. The stochastic properties of input spike trains control neuronal arithmetic. Biol Cybern 106: 111-122, 2012.

Chou YH, Spletter ML, Yaksi E, Leong JCS, Wilson RI, Luo L. Diversity and wiring variability of olfactory local interneurons in the Drosophila antennal lobe. Nat Neurosci 13: 439-449, 2010.

Christensen TA, Waldrop BR, Harrow ID, Hildebrand JG. Local interneurons and information processing in the olfactory glomeruli of the moth Manduca sexta. J Comp Physiol B 173: 385-399, 1993.

Connors BW, Gutnick MJ. Intrinsic firing patterns of diverse neocortical neurons. Trends Neurosci 13: 99-104, 1990.

Dacks AM, Reisenman CE, Paulk AC, Nighorn AJ. Histamin-immunoreactive local neurons in the antennal lobes of the hymenoptera. J Comp Neurol 518: 2917-2933, 2010.

Distler PG, Boeckh J. Synaptic connections between identified neuron types in the antennal lobe glomeruli of the cockroach, Periplaneta Americana. I. Uniglomerular projection neurons. J Comp Neurol 378: 307-319, 1997.

Fernandez PC, Locatelli FF, Person-Rennell N, Deleo G, Smith BH. Associative conditioning tunes transient dynamics of early olfactory processing. J Neurosci 29: 10191-10202, 2009.

Flanagan D, Mercer AR. Morphology and response characteristics of neurons in in the deutocerebrum of the brain in the honeybee Apis mellifera. J Comp Physiol A 164: 483-494, 1989b.

Fonta C, Sun XJ, Masson C. Morphology and spatial distribution of bee antennal lobe interneurones responsive to odours. Chem Senses 18: 101119, 1993.

Galizia CG. Insect olfaction. In: The Senses: A Comprehensive Reference, edited by Basbaum AI, Kaneko A, Shepherd GM, Westheimer G, Albrigh TD, Masland RH, Dallos P, Oertel D, Firestein S, Beauchamp GK, Bushnel MC, Kaas JH, Gardner E. New York: Elsevier 2008, vol. 4, p. 725-770.

Galizia CG, Kimmerle B. Physiological and morphological characterization of honeybee olfactory neurons combining electrophysiology, calcium imaging and confocal microscopy. J Comp Physiol A 190: 21-38, 2004.

Galizia CG, Rössler W. Parallel olfactory systems in insects: anatomy and function. Annu Rev Entomol 55: 399-420, 2010.

Guerrieri F, Schubert M, Sandoz JC, Giurfa M. Perceptual and neura olfactory similarity in honeybees. PLoS Biol 3: e60, 2005.

Haddad R, Khan R, Takahashi YK, Mori K, Harel D, Sobel N. A metric for odorant comparison. Nat Methods 5: 425-429, 2008.

Holt GR, Softky WR, Koch C, Douglas RJ. Comparison of discharge variability in vitro and in vivo in cat visual cortex neurons. $J$ Neurophysio 75: $1806-1814,1996$.

Homberg U, Montague RA, Hildebrand JG. Anatomy of antenno-cerebral pathways in the brain of the sphinx moth Manduca Sexta. Cell Tissue Res 254: 255-281, 1988.

Hu A, Zhang W, Wang Z. Functional feedback from mushroom bodies to antennal lobes in the Drosophila olfactory pathway. Proc Natl Acad Sci U $S$ A 107: 10262-10267, 2010.

Husch A, Paehler M, Fusca D, Paeger L, Kloppenburg P. Distinct electrophysiological properties in subtypes of nonspiking olfactory local interneurons correlate with their cell type-specific $\mathrm{Ca}^{2+}$ current profiles. J Neurophysiol 29: 11582-11592, 2009.

Joseph J, Dunn F, Stopfer M. Spontaneous olfactory receptor neuron activity determines follower cell response properties. J Neurosci 32: 2900-2910, 2012 .

Kazama H, Wilson RI. Origins of correlated activity in an olfactory circuit. Nat Neurosci 12: 1136-1144, 2009

Kelber C, Rössler W, Kleineidam CJ. Phenotypic plasticity in number of glomeruli and sensory innervation of the antennal lobe in leaf-cutting ant workers (A. vollenweideri). Dev Neurobiol 70: 222-234, 2010.

Kreissl S, Strassser C, Galizia CG. Allatostatin immunoreactivity in the honeybee brain. J Comput Neurol 518: 1391-1417, 2010.
Krofczik S, Menzel R, Nawrot MP. Rapid odor processing in the honeybee antennal lobe network. Front Comp Neurosci 2: 1-13, 2009.

Laurent G. A dendritic gain control mechanism in axonless neurons of the locust, Schistocerca americana. J Physiol 470: 45-54, 1993.

Lei H, Reisenman CE, Wilson CH, Gabbur P, Hildebrand JG. Spiking patterns and their functional implications in the antennal lobe of the tobacco hornworm manducasexta. PLos One 6: e23382, 2011.

Leitch B, Laurent G. GABAergic synapses in the antennal lobe and mushroom body of the locust olfactory system. J Comp Neurol 372: 487-514, 1996.

Llinás RR. The intrinsic electrophysiological properties of mammalian neurons: insights into central nervous system function. Science 242: 1654 1664, 1988.

Malun D. Synaptic relationships between GABA-immunoreactive neurons and an identified uniglomerular projection neuron in the antennal lobe of Periplaneta americana: a double-labeling electron microscopic study. Histochemistry 96: 197-207, 1991.

Markram H, Toledo-Rodriguez M, Wang Y, Gupta A, Silberberg G, Wu C. Interneurons of the neocortical inhibitory system. Nat Rev Neurosci 5 : 793-807, 2004

Martin JP, Beyerlein A, Dacks AM, Reisenman CE, Riffell J, Lei H, Hildebrand JG. The neurobiology of insect olfaction: sensory processing in a comparative context. Prog Neurobiol 95: 427-447, 2011.

Martinez D, Montejo N. A model of stimulus-specific neural assemblies in the insect antennal lobe. PLoS Comput Biol 4: e10000139, 2008.

Matthews BW. Comparison of the predicted and observed secondary structure of T4 phage lysozyme. Biochim Biophys Acta 405: 442-451, 1975.

McCormick DA, Connors BW, Lighthall JW, Prince DA. Comparative electrophysiology of pyramidal and sparsely spiny stellate neurons of the neocortex. J Neurophysiol 54: 782-806, 1985.

Meier R, Egert U, Aertsen A, Nawrot MP. FIND-a unified framework for neural data analysis. Neural Netw 28: 1085-1093, 2008.

Menzel R, Rybak J. Antennal lobe of the honeybee. In: Handbook of Brain Microcircuits, edited by Sheperd G, Grillner S. New York: Oxford University Press, 2010, p. 433-438.

Meyer A. Characterisation of Local Interneurons in the Antennal Lobe of the Honeybee (PhD thesis). Konstanz, Germany: University of Konstanz, 2011. http://kops.ub.uni-konstanz.de/handle/urn:nbn:de:bsz:352-162535.

Meyer A, Brill M, Rössler W, Nawrot MP. Do morphologically distinct projection neurons in the honey bee antennal lobe spike differently? In: Front Comput Neurosci Conference Abstract: Bernstein Conference 2012. doi: 10.3389/conf.fncom.2012.55.00096.

Meyer A, Galizia CG. Elemental and configural olfactory coding by antennal lobe neurons of the honeybee (Apis mellifera). J Comp Physiol A 198 159-171, 2012

Nagel KI, Wilson RI. Biophysical mechanisms underlying olfactory receptor neuron dynamics. Nat Neurosci 14: 208-216, 2011.

Nässel DR, Homberg U. Neuropeptides of the insect brain. Cell Tissue Res 326: 1-24, 2006.

Nawrot MP. Analysis and interpretation of interval and count variability in neural spike trains. In: Analysis of Parallel Spike Trains, edited by Grün S, Rotter S. 2010, New York: Springer, p. 37-58

Nawrot MP. Dynamics of sensory processing in the dual olfactory pathway of the honeybee. Apidologie (Celle) 43: 269-291, 2012.

Nawrot M, Aertsen A, Rotter S. Single-trial estimation of neuronal firing rates: from single-neuron spike trains to population activity. $J$ Neurosci Methods 94: 81-92, 1999.

Nawrot MP, Aertsen A, Rotter S. Elimination of response latency variability in neuronal spike trains. Biol Cybern 88: 321-334, 2003.

Nawrot MP, Boucsein C, Rodriguez-Molina V, Riehle A, Aertsen A, Rotter S. Measurement of variability dynamics in cortical spike trains. $J$ Neurosci Methods 169: 374-390, 2008.

Ng M, Roorda RD, Lima SQ, Zemelman BV, Morcillo P, Miesenböck G. Transmission of olfactory information between three populations of neurons in the antennal lobe of the fly. Neuron 36: 463-474, 2002.

Olsen SR, Wilson RI. Cracking neural circuits in a tiny brain: new approaches for understanding the neural circuitry of Drosophila. Trends Neurosci 31 : 512-520, 2008a.

Olsen SR, Wilson RI. Lateral presynaptic inhibition mediates gain control in an olfactory circuit. Nature 452: 956-960, 2008 b.

Parzen E. On estimation of a probability density function and mode. Ann Math Stat 33: 1065-1076, 1962.

Pearson K. On lines and planes of closest fit to systems of points in space. Philos Mag (Abingdon) 2: 559-572, 1901. 
Pippow A, Husch A, Pouzat C, Kloppenburg P. Differences of $\mathrm{Ca}^{2+}$ handling properties in identified central olfactory neurons of the antennal lobe. Cell Calcium 46: 87-98, 2009.

Ponce-Alvarez A, Kilavik BE, Riehle A. Comparison of local measures of spike time irregularity and relating variability to firing rate in motor cortical neurons. J Comput Neurosci 29: 351-365, 2010.

Pouzat C, Delescluse M, Viot P, Diebolt J. Improved spike-sorting by modeling firing statistics and burst-dependent spike amplitude attenuation: a Markov chain Monte Carlo approach. J Neurophysiol 91: 2910-2928, 2004.

Renart A, de la Rocha J, Bartho P, Hollender L, Parga N, Reyes A, Harris KD. The asynchronous state in cortical circuits. Science 327: 587-590, 2010.

Riffell J, Lei H, Christensen T, Hildebrand JG. Characterization and coding of behaviorally significant odor mixtures. Curr Biol 19: 335-340, 2009.

Rössler W, Brill MF. Parallel processing in the honeybee olfactory pathway: structure, function, and evolution. J Comp Physiol A Neuroethol Sens Neural Behav Physiol. In press, 2013.

Rössler W, Zube C. Dual olfactory pathway in Hymenoptera: evolutionary insights from comparative studies. Arthropod Struct Dev 40: 349-357, 2011.

Ruigrok TJH, Hensbroek R, Simpson JI. Spontaneous activity signatures of morphologically identified interneurons in the vestibulocerebellum. $\mathrm{J} \mathrm{Neu}$ rosci 31: 712-724, 2011.

Rybak J. The digital honey bee brain atlas. In: Honeybee Neurobiology and Behavior, edited by Galizia CG, Eisenhardt D, Giurfa M. Heidelberg, Germany: Springer, 2012, p. 125-140.

Rybak J, Menzel R. Mushroom body of the honeybee. In: Handbook of Brain Microcircuits, edited by Sheperd G, Grillner S. New York: Oxford University Press, 2010, p. 433-438.

Sachse S. Topography and dynamics of the olfactory system. In: Microcircuits: The Interface between Neurons and Global Brain Function. Dahlem Workshop Report 93, edited by Grillner S. Cambridge, MA: MIT, 2006, p. 251-273.

Sachse S, Galizia CG. Role of inhibition for temporal and spatial odor representation in olfactory output neurons: a calcium imaging study. $J$ Neurophysiol 87: 1106-1117, 2002.

Sachse S, Galizia CG. The coding of odour-intensity in the honeybee antennal lobe: local computation optimizes odour representation. Eur J Neurosci 18 : 2119-2132, 2003.

Sanes JR, Hildebrand JG. Structure and development of antennae in a moth, Manduca sexta. Dev Biol 51: 282-299, 1976b.

Savitzky A, Golay MJ. Smoothing and differentiation of data by simplified least squares procedures. Anal Chem 36: 1627-1639, 1964.

Schäfer S, Bicker G. Distribution of GABA-like immunoreactivity in the brain of the honeybee. J Comp Neurol 246: 287-300, 1986.
Schmuker M, Schneider G. Processing and classification of chemical data inspired by insect olfaction. Proc Natl Acad Sci U S A 104: 20285-20289, 2007

Seki Y, Kanzaki R. Comprehensive morphological identification and GABA immunocytochemistry of antennal lobe local interneurons in Bombyx mori. J Comp Neurol 506: 93-101, 2008.

Seki Y, Rybak J, Wicher D, Sachse S, Hansson BS. Physiological and morphological characterization of local interneurons in the Drosophila antennal lobe. J Neurophysiol 104: 1007-1019, 2010.

Shadlen MN, Newsome WT. The variable discharge of cortical neurons: implications for connectivity, computation, and information coding. $\mathrm{J} \mathrm{Neu}$ rosci 18: 3870-3896, 1998.

Shepherd GM, Migliore M, Willhite DC. Olfactory bulb. In: Handbook of Brain Microcircuits, edited by Sheperd G, Grillner S. New York: Oxford University Press, 2010, p. 251-262.

Stevens CF, Zador AM. Input synchrony and the irregular firing of cortical neurons. Nat Neurosci 1: 210-217, 1998.

Stocker RF. The organization of the chemosensory system in Drosophila melanogaster: a review. Cell Tissue Res 275: 3-26, 1994.

Stocker RF, Heimbeck G, Gendre N, de Belle JS. Neuroblast ablation in Drosophila GAL4 lines reveals origins of olfactory interneurons. J Neurobiol 32: 443-456, 1997.

Stocker RF, Lienhard MC, Borst A, Fischbach KF. Neuronal architecture of the antennal lobe in Drosophila melanogaster. Cell Tissue Res 262: 9-34, 1990.

Stopfer M, Jayaraman V, Laurent G. Intensity versus identity coding in an olfactory system. Neuron 39: 991-1004, 2003.

Strowbridge BW. Linking local circuit inhibition to olfactory behavior: a critical role for granule cells in olfactory discrimination. Neuron 65: 295 297, 2010.

Strube-Bloss MF, Herrera-Valdez MA, Smith BH. Ensemble response in mushroom body output neurons of the honey bee outpaces spatiotemporal odor processing two synapses earlier in the antennal lobe. PLos One 7: e50322, 2012

van Vreeswijk C, Sompolinsky H. Chaos in neural networks with balanced excitatory and inhibitory activity. Science 274: 1724-1726, 1996.

Ward JH. Hierarchical grouping to optimize an objective function. J Am Stat Assoc 58: 236-244, 1963

Wilson RI, Mainen ZF. Early events in olfactory processing. Annu Rev Neurosci 29: 163-201, 2006.

Witthöft W. Absolute anzahl und verteilung der zellen im hirn der honigbiene. Z Morphol Tiere 61: 160-184, 1967.

Zube C, Rössler W. Caste- and sex-specific adaptations within the olfactory pathway in the brain of the ant Camponotus floridanus. Arthropod Struct Dev 37: 469-479, 2008. 